\title{
Vocal Communication in Hummingbirds
}

\author{
Fernanda G. Duque ${ }^{a, b}$ Laura L. Carruth ${ }^{a}$ \\ a Neuroscience Institute, Georgia State University, Atlanta, GA, USA; ${ }^{6}$ Biology Department, Hofstra University, \\ Hempstead, NY, USA
}

\section{Keywords \\ Vocal learning · High-frequency vocalizations · Birds . Hearing $\cdot$ Auditory processing}

\begin{abstract}
Hummingbirds exhibit complex vocal repertoires that they use in their social interactions. Furthermore, they are capable of vocal production learning, an ability they share with songbirds, parrots, some non-oscine birds, and some mammals including humans. Despite these characteristics, hummingbirds have not received the same attention as other birds, especially songbirds and parrots, in the study of vocal communication. Recent studies are advancing our knowledge of vocal communication in hummingbirds showing that these birds exhibit complex social learning and extraordinary abilities for vocal production. Moreover, vocal production learning in hummingbirds provides opportunities to study the evolution and diversification of vocal signals because of the presence of dialects in some species. In addition, the presence of high-frequency vocalizations in some hummingbirds underscores the relevance of these birds to study the evolution of communication signals and sensory adaptations. Not only do some species vocalize at unusually high
\end{abstract}

frequencies compared to other birds, but evidence also shows that at least one hummingbird species can hear these sounds, defying what we knew about avian hearing capabilities. Detailed descriptions of the hummingbird syrinx have shown that this organ exhibits homologous structures to those found in the syrinx of oscines, showing that vocal complexity in hummingbirds requires complex syringeal musculature. However, more research is needed to determine whether hummingbirds have unique adaptations that confer exceptional vocal and hearing abilities exceeding those found in other groups of birds. $\quad 2022 \mathrm{~S}$. Karger AG, Basel

\section{Introduction}

Hummingbirds, like other birds, exhibit a wide range of social behaviors and use vocal communication to mediate their interactions [Ornelas et al., 2002; Ferreira et al., 2006; Lara et al., 2015]. Although vocal communication is common among animals [Bradbury and Vehrencamp, 2011], the ability to learn vocalizations by imitation has evolved independently in a few groups of birds and mammals [Janik and Slater, 1997; Jarvis, 2004; Nowicki and 
Searcy, 2014; ten Cate, 2021]. Hummingbirds (Apodiformes: Trochilidae) [Chen and Field, 2020] are among the birds that exhibit vocal production learning, an ability also present in songbirds (order Passeriformes), parrots (order Psittaciformes) [Baptista and Schuchmann, 1990; Jarvis, 2004; Salinas-Melgoza and Wright, 2012; Bradbury and Balsby, 2016], some non-oscine species [ten Cate, 2021], and most recently, described in a species of duck [ten Cate and Fullagar, 2021]. Although previously understudied with respect to their vocal abilities, hummingbirds are becoming the focus of numerous studies on vocal production. Here, we summarize the research in vocal communication in hummingbirds by addressing different aspects of their vocal abilities, including learning and song variation, the production of highfrequency vocalizations, and the neural and vocal structures that facilitate these behaviors.

\section{Vocal Repertoires in Hummingbirds}

Birds produce vocalizations that vary in complexity and function, referred to as songs and calls. Songs are broadly defined as long, complex vocalizations mostly produced by breeding males, whereas calls are defined as simpler vocalizations that both sexes produce throughout the year [Catchpole and Slater, 2008]. These definitions, however, have multiple exceptions such as singing females [Riebel, 2003; Slater and Mann, 2004; Wilkins et al., 2020], and species in which males and females duet, often throughout the year [Fedy and Stutchbury, 2005; Mann et al., 2006; Baldassarre et al., 2016]. The definition of song has also been associated with vocal production learning, so that vocal learners produce more complex, learned songs and innate calls whereas other species only produce innate vocalizations or calls [Catchpole and Slater, 2008; Nowicki and Searcy, 2014].

"Vocal repertoire" in birds has also been traditionally tied to the concept of song, so it is defined as the set of song types that males of a species produce [Kroodsma, 2004; Catchpole and Slater, 2008]. Nevertheless, this definition excludes all other vocalizations that individuals of a species produce and that serve a social function. For the purpose of this review, we maintain the distinction between songs as complex vocalizations and calls as simpler signals, but we define "vocal repertoire" as the complete set of vocalization types produced by individuals of both sexes in a species. This more inclusive definition is in line with studies in vocal communication across other taxonomic groups [Gros-Louis et al., 2008; Pettitt et al., 2012;
Jones et al., 2020]. Giving more relevance to simpler calls can also be informative for understanding signal evolution and the selection pressures that shape vocal signals [Ryan et al., 1982].

Many hummingbird species exhibit rich repertoires of vocalizations that serve different social functions and vary in structure, complexity, and spectral content [Ficken et al., 2002; Ornelas et al., 2002; Ferreira et al., 2006; Lara et al. 2015]. They are produced in specific social contexts, mainly territorial defense, courtship, parent-offspring interactions, foraging, and announcing a potential threat such as a predator [Pytte and Ficken, 1994; Ficken et al., 2002; Ortiz-Crespo, 2003; Ferreira et al., 2006; Bradbury and Vehrencamp, 2011].

Territorial signals help animals defend their territories and resources from intruders [Hunter, 2008; Bradbury and Vehrencamp, 2011]. These signals can vary in complexity, from single-note vocalizations or trills produced at rapid succession to more elaborate songs with multiple frequency-modulated elements [Ficken et al., 2002; Ferreira et al., 2006]. While territorial calls are mostly used to prevent aggressive encounters, if aggression escalates, some hummingbirds increase the rate at which they produce their calls, often aggressively chasing the intruder away from their territory [Wolf, 1969; Ferreira et al., 2006]. During the breeding season, hummingbirds also produce characteristic courtship sounds to attract females, usually in tandem with complex visual displays [Pytte and Ficken, 1994; Clark and Feo, 2010; Feo and Clark, 2010; Hogan and Stoddard, 2018].

\section{High-Frequency Vocalizations}

As part of their repertoire, some hummingbird species produce vocalizations with fundamental frequencies beyond the average range of vocal production in most birds $(2-8 \mathrm{kHz})$ [Dooling, 1982, 2004], known as high-frequency vocalizations. In this review, high-frequency vocalizations are defined as any vocal sound produced at fundamental frequencies above $8 \mathrm{kHz}$. High-frequency vocalizations in hummingbirds have defied our knowledge on avian vocal production and hearing capabilities, sparking a renewed interest in understanding vocal behavior in these birds. The courtship song in the Costa's hummingbird (Calypte costae) [Wells et al., 1978] may be one of the early accounts of high-frequency vocalizations in hummingbirds. Then, 2 decades ago, Schuchmann [1999] mentioned that the black jacobin (Florisuga fusca) produced high-frequency vocalizations [Schuchmann, 1999], which were documented and described in detail a few years ago [Olson et al., 2018]. Other accounts of high- 


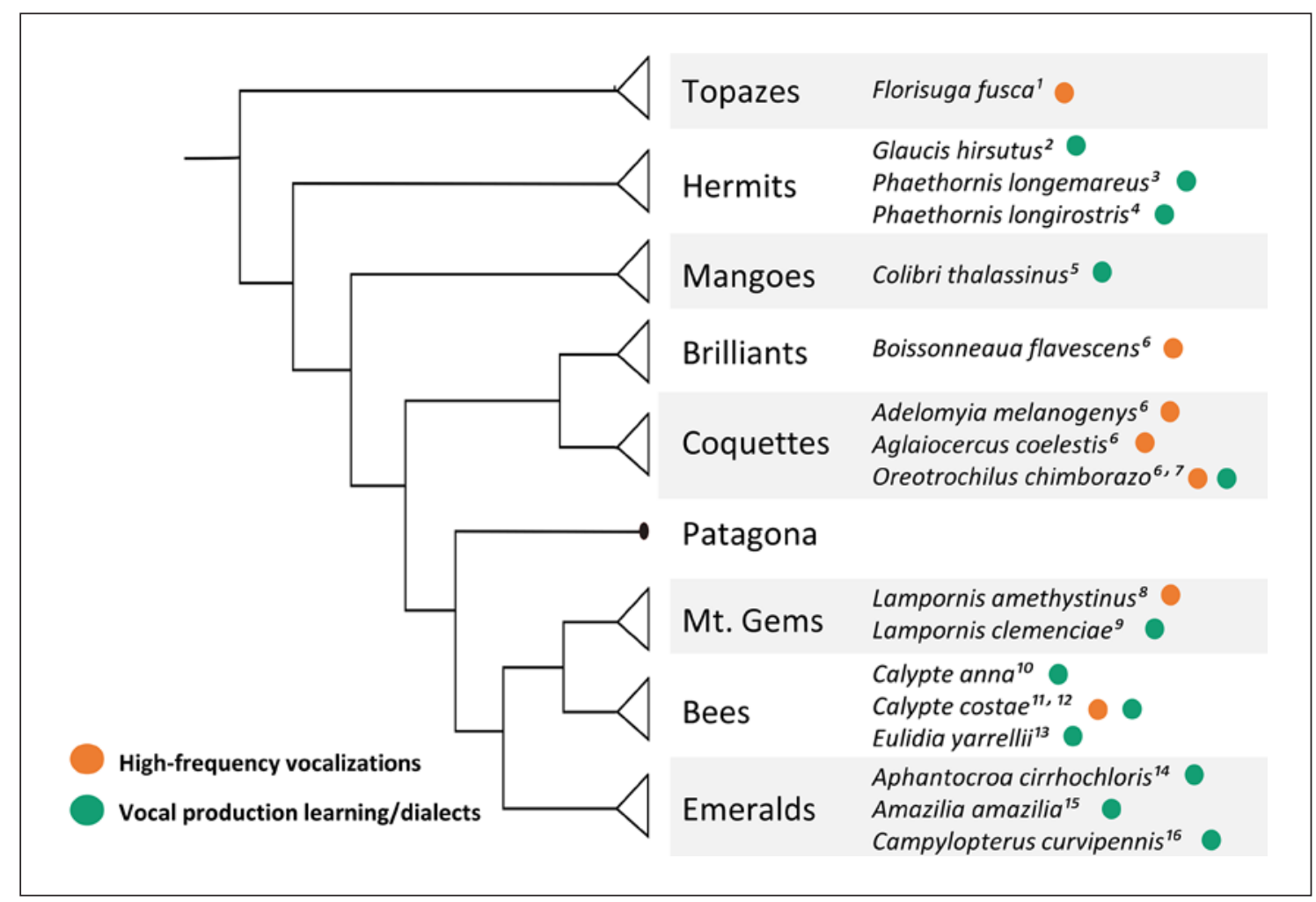

Fig. 1. Simplified phylogeny showing the main clades in the Trochilidae family. Orange circles highlight species that produce high-frequency vocalizations, while green circles show species with documented vocal learning or dialects. Phylogeny based on McGuire et al. [2007, 2014]. ${ }^{1}$ Olson et al. [2018]; ${ }^{2}$ Jarvis et al. [2000]; ${ }^{3}$ Wiley [1971]; ${ }^{4}$ Araya-Salas and Wright [2013]; ${ }^{5}$ Lara et al. [2015]; ${ }^{6}$ Duque et al. [2018]; ${ }^{7}$ Duque et al. [2020a]; ${ }^{8}$ Ornelas et al. [2002]; ${ }^{9}$ Ficken et al. [2002]; ${ }^{10}$ Baptista and Schuchmann [1990]; ${ }^{11}$ Clark and Feo [2010]; ${ }^{12}$ Johnson and Clark [2020]; ${ }^{13}$ Clark et al. [2013]; ${ }^{14}$ Jarvis et al. [2000]; ${ }^{15} \mathrm{Gahr}[2000] ;{ }^{16}$ González and Ornelas [2005].

frequency vocalizations include the feeding call and song of the amethyst-throated hummingbird (Lampornis amethystinus) [Ornelas et al., 2002], and the song and "scolding" calls of the Chilean woodstar (Eulidia yarrellii) [Clark et al., 2013]. Recently, high-frequency vocalizations were also discovered in four species of Andean hummingbirds: the Ecuadorian hillstar (Oreotrochilus chimborazo), violet-tailed sylph (Aglaiocercus coelestis), speckled hummingbird (Adelomyia melanogenys), and buff-tailed coronet (Boissonneaua flavescens) [Duque et al., 2018] (Fig. 1).

High-frequency vocalizations in hummingbirds vary in complexity, ranging from simple single-note vocalizations to rapidly frequency-modulated sounds [Clark and Feo, 2010; Duque et al., 2018; Olson et al., 2018]. Highfrequency vocalizations are used by some species for territorial defense [Clark et al., 2013; Duque et al., 2018; Olson et al., 2018], whereas other hummingbirds with more elaborate vocalizations use these sounds for courtship.
For instance, the buff-tailed coronet (B. flavescens) and the speckled hummingbird (A. melanogenys) in the Andes produce simple high-frequency vocalizations in a territorial context [Duque et al., 2018]. As aggression escalates, individuals of both species decrease their inter-call intervals while increasing the pitch of their vocalizations [Duque, pers. observation]. These rapid changes in call interval and pitch suggest that these species use these features to encode information about social interactions and require further investigation. The two Andean species as well as the black jacobin ( $F$. fusca) in the Atlantic Forest do not exhibit sexually dimorphic plumage. Thus, it is unclear whether both males and females in these species can produce high-frequency vocalizations, and if they use these signals in social contexts other than territorial defense.

In contrast, the most complex vocalization produced entirely in the high-frequency range is the song of the Ecuadorian hillstar (O. chimborazo), composed of frequen- 
cy-modulated introductory notes and trills [Duque et al., 2018]. These vocalizations are most likely used as shortrange communication signals since their acoustic properties do not allow them to travel far in their environment [Duque et al., 2021]. Ecuadorian hillstar males produce high-frequency vocalizations during both territorial defense and courtship displays. In territorial contexts, males establish preferred perches that they use to broadcast their high-frequency song and defend their territory [Duque et al., 2018]. When males visit the females' territories, the former produce high-frequency songs while hovering in front of the female as part of the courtship display [Duque et al., 2020b]. Figure 2 shows a spectrogram of the high-frequency song of the Ecuadorian hillstar and a schematic of its courtship display. Costa's hummingbird males also produce high-frequency vocalizations paired with acrobatic visual displays as part of their courtship toward females [Clark and Feo, 2010].

The complex song of the blue-throated hummingbird (Lampornis clemenciae) consists of low- and high-frequency elements ranging from approximately $3-20 \mathrm{kHz}$ as well as some ultrasonic components $(>20 \mathrm{kHz})$ [Pytte et al., 2004]. The biological relevance of the high-frequency and ultrasonic elements in the song, however, is still unclear. The remarkable song of the blue-throated hummingbird contrasts with those categorized as high-frequency vocalizations in other species because the latter are produced almost exclusively in the high-frequency range. Like the high-frequency notes in the song of the blue-throated hummingbird, high-frequency vocalizations in other species also have harmonics in the ultrasonic range (Fig. 2a), but their relevance remains unknown. So far, high-frequency vocalizations have been found in species belonging to the most basal clade in the hummingbird phylogeny, as well as in those that have undergone recent diversification, such as the Andean clade (Brilliants and Coquettes) or the Mountain Gems and Bee clade (Fig. 1). More data are necessary to confirm whether other species of hummingbirds belonging to other clades also produce high-frequency vocalizations.

\section{Female Vocalizations}

Interest among researchers for singing in female birds including hummingbirds has grown in recent years [Ficken et al., 2000; Riebel, 2003; Catchpole and Slater, 2008; Clark et al., 2018b; Wilkins et al., 2020]. Blue-throated hummingbird (L. clemenciae) females exhibit complex songs that differentiate in structure and frequency content from those of males [Ficken et al., 2000]. Females produce these vocalizations near males, suggesting that these signals have a social function. In addition, some Costa's hummingbird females also produce vocalizations that resemble those of males in a territorial context [Clark et al., 2018b]. Although this feature was present in 2 out of 10 females examined, it emphasizes the need to further study the role of female vocalizations in hummingbirds. In the Ecuadorian hillstar, females produce the same vocalizations as males except for the high-frequency courtship song [Duque, unpubl. data]. More work is needed to understand how widespread female vocalizations are across hummingbirds and their role in the social dynamics of the species that produce them.

\section{Other Acoustic Signals}

Some species of hummingbirds not only use vocal sounds to communicate with conspecifics, but they also produce sounds with their tail and wing feathers [Bostwick and Prum, 2003; Hunter, 2008; Clark and Feo, 2010; Clark, 2011]. These sounds are produced during acrobatic courtship displays and are distinctive in each species [Pytte and Ficken, 1994; Feo and Clark, 2010]. Furthermore, feathers are optimized to produce sounds under the specific conditions that each species' acrobatic display renders [Clark et al., 2018a]. In some species, such as the Anna's hummingbird (Calypte anna) and the Costa's hummingbird (C. costae), vocalizations closely resemble tail and wing sounds suggesting that males learned to imitate the feather sounds that they already produced during courtship displays and that were attractive to conspecific females [Clark and Feo, 2010; Clark et al., 2018a]. Nonetheless, female preference or perception of either vocalizations or other courtship sounds has not been tested in hummingbirds yet.

\section{Song Variation and Vocal Production Learning}

Hummingbirds are among the few vertebrate groups in which vocal production learning has evolved [Nowicki and Searcy, 2014; Janik and Knörnschild, 2021; ten Cate, 2021]. Vocal learning facilitates song variation within a species, and these song variants or dialects can be found across populations or groups of individuals of the same species. Dialects are more common among vocal production learners and are present in humans, whales, dolphins, birds, and in some vocal non-learners [Marler and Tamura, 1962; Capranica et al., 1973; Janik, 2000; Ford, 2011; Burridge, 2017]. Dialects in vocal non-learners such as frogs or singing mice result from genetic variation across populations of the same species [Wycherley et al., 


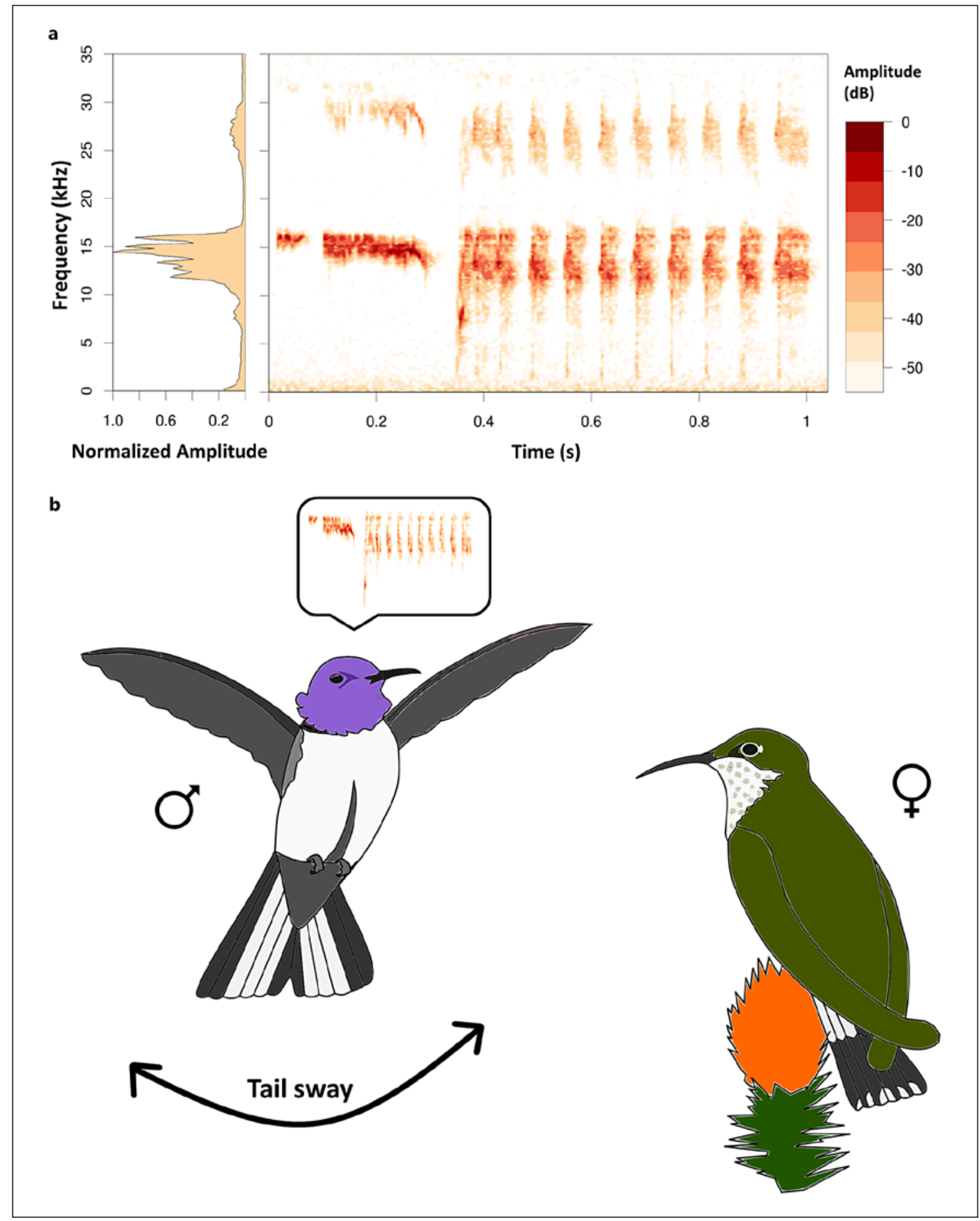

Fig. 2. High-frequency vocalizations in the Ecuadorian hillstar. a Power spectrum (left) and spectrogram (right) of a high-frequency vocalization produced by a male Ecuadorian hillstar showing the fundamental frequency $\left(\mathrm{F}_{0}=13.4 \mathrm{kHz} \pm 0.47\right.$, mean $\left.\pm \mathrm{SE}\right)$ [Duque et al., 2018], and a harmonic in the ultrasonic range. b Schematic of the courtship display in the Ecuadorian hillstar, showing a male hovering in from of a female, swaying its tail and singing the high-frequency vocalization [Duque et al., 2020a, b]. Males also produce high-frequency vocalizations while standing on high perches in their own territory [Duque et al., 2018]. 
2002; Campbell et al., 2010]. In contrast, vocal learners imitate the sounds that other conspecifics produce [Nottebohm, 1972; Nelson, 2000; Planqué et al., 2014]. Hummingbirds also exhibit song dialects, and this feature helped researchers to elucidate the presence of vocal learning in some species [Snow, 1968; Wiley, 1971; Baptista and Schuchmann, 1990; Gaunt et al., 1994; González and Ornelas, 2005; Araya-Salas and Wright, 2013; Lara et al., 2015].

Anna's hummingbirds (C. anna), for example, exhibit dialects across localities [Baptista and Schuchmann, 1990]. In captivity, hummingbirds raised together developed more stereotypical songs with multiple shared song elements, while the song of an Anna's hummingbird raised in isolation resulted in a less stereotyped song than those found in the wild [Baptista and Schuchmann, 1990]. These results showed that males in this species learn their songs from conspecifics, and that social interactions are important for learning. More recently, Johnson and Clark [2020] described the ontogeny of vocal production learning in the Costa's hummingbird (C. costae), showing that sensitive early developmental periods for song learning in this species are similar to those found in many songbirds. Moreover, passive playback of song alone was not sufficient to elicit learning in juveniles, but exposure to song and a conspecific adult male were necessary for song learning [Johnson and Clark, 2020]. Both studies highlight similarities in the learning process of hummingbirds with that of other animals such as songbirds, which also exhibit early sensitive periods for vocal learning. They also emphasize the role of social interactions for vocal production learning in hummingbirds despite not exhibiting paternal care. Contrasting with species that exhibit critical periods for vocal learning early in development [Johnson et al., 2002; Johnson and Clark, 2020], some animals, including some species of hummingbirds, can learn vocalizations as adults [Mountjoy and Lemon, 1991; Farabaugh et al., 1994; Marler et al., 1994]. For instance, long-billed hermits (Phaethornis longirostris) are known for learning and switching song types even as adults while lekking with conspecifics [Araya-Salas and Wright, 2013].

While there are few studies focusing on vocal learning in hummingbirds [Baptista and Schuchmann, 1990; Johnson and Clark, 2020], research shows that song dialects are widespread in hummingbirds across phylogenetic clades. Moreover, there is evidence that in some species dialects evolved faster than other traits and are present despite gene flow across populations [González and Ornelas, 2005, 2014; González et al., 2011; Lara et al., 2015; Duque et al., 2020a]. These results show that dialects are not the result of genetic drift and highlight the role of vocal production learning in the evolution of song in these species. Moreover, the coevolution of vocalizations and visual signals among individuals of highly social species such as the long-billed hermit exemplifies the complex learning abilities that some hummingbirds exhibit [Araya-Salas et al., 2019]. Figure 1 shows a hummingbird phylogeny and the species of hummingbirds exhibiting dialects and vocal production learning. More studies on the learning abilities of hummingbirds are necessary to determine whether this trait is widespread across clades in the hummingbird phylogeny. For instance, no systematic study has been conducted to characterize in detail the vocal repertoire or learning abilities of the giant hummingbird (Patagona gigas), the lone member of the Patagona clade (Fig. 1), except for recordings reported in open databases. Targeting clades for which there is a lack of information regarding vocal production learning and other vocal features is key to develop a complete understanding of how vocal communication has diversified in hummingbirds.

\section{The Vocal Organ: The Syrinx}

Physical constraints influence vocal communication, either facilitating or restricting the vocal range of animals [Ryan and Brenowitz, 1985]. Across multiple taxa, an acoustic allometry has been observed, so that smaller animals produce vocalizations at higher frequencies than their larger counterparts [Bradbury and Vehrencamp, 2011; Gingras et al., 2013]. This allometry is explained by a positive correlation between body size and the size of the vocal organ, and it has been extensively documented among multiple avian groups [Ryan and Brenowitz, 1985; Goller and Riede, 2013]. At the moment, no systematic study has been published determining whether body size correlates with vocal production in hummingbirds. Preliminary data suggest that in these birds body size does not predict vocal production [Duque and Carruth, 2021]. The absence of this acoustic allometry in hummingbirds pinpoints to potential adaptations that have enabled the production of wide ranges of frequencies in hummingbirds.

Although birds have both a larynx and a syrinx, the syrinx is the avian vocal organ. In most birds, the syrinx is located in the thorax [Düring et al., 2013], but in hummingbirds it is positioned in the neck outside of the tho$\operatorname{rax}$ [Zusi, 2013; Monte et al., 2020; Riede and Olson, 2020]. It is still unknown why the hummingbird syrinx has this position, but the hummingbird's enlarged heart, which occupies a big part of the chest cavity, may be the 
main reason [Monte et al., 2020]. Although the hummingbird syrinx shows convergence with the syrinx in songbirds, including the presence of intrinsic muscles [Monte et al., 2020; Riede and Olson, 2020], there are subtle differences that may account in part for the diversity of vocalizations and the frequencies that hummingbirds can produce. For instance, there are small differences in the position of the syrinx in the neck as well as syrinx measurements among species of hummingbirds that exhibit complex songs compared to closely related species that produce simple calls and have lost the ability to sing [Riede and Olson, 2020]. The hummingbird syrinx also exhibits pairs of intrinsic muscles with ventro-dorsal orientation, and it lacks the sterno-tracheal muscles [Monte et al., 2020; Riede and Olson, 2020]. Biomechanical properties of the intrinsic muscles, characterized in oscines as superfast muscles may be responsible for rapidly frequency-modulated motifs in high-frequency vocalizations [Monte et al., 2020]. More comparative studies are needed to understand the morphological and physiological properties of the syrinx of hummingbirds producing high-frequency vocalizations and those of closely related species that sing low-frequency sounds.

\section{Hearing and the Hummingbird Brain}

Vocal communication and particularly vocal learning require the presence of specialized interconnected brain nuclei that facilitate song control and auditory perception [Vicario and Nottebohm, 1988]. In 2000, two studies independently confirmed the presence of song system nuclei in the hummingbird brain homologous to those found in the brains of songbirds. Using a comparative approach that included vocal learners and non-learners, Gahr [2000] employed estrogen receptors to map these nuclei in the hummingbird brain. Jarvis et al. [2000] also showed the presence of these nuclei by inducing the expression of the immediate-early gene zenk in the song system in response to playback of conspecific vocalizations and during singing bouts. Both studies confirmed that the hummingbird brain exhibits specialized regions involved in song learning and production like those present in songbirds (online suppl. Fig. 1; for all online suppl. material, see www.karger.com/doi/10.1159/000522148). Online supplementary Table 1 shows the nomenclature for the song system nuclei in hummingbirds and songbirds [Jarvis et al., 2000; Reiner et al., 2004].

Although brain nuclei for song control and auditory perception have been identified in hummingbirds, it has been harder to obtain detailed characterizations of their auditory sensitivity. Measurements of auditory sensitivity using auditory brainstem responses (ABRs) in the blue-throated hummingbird (L. clemenciae) showed that this species hears best at low frequencies, matching only the low-frequency components of its courtship song but not those produced at high frequencies [Pytte et al., 2004]. Similar sensitivity was observed in the rubythroated hummingbird (Archilochus colubris), which produces a song with a fundamental frequency of $3 \mathrm{kHz}$ and hears best at the same frequency [Lohr and Dooling, 2004]. It is possible that some hummingbirds have a hearing range restricted to lower frequencies to match their vocal production or because the high-frequency notes in their songs do not have biological relevance for the species [Dooling, 1982, 2004]. However, the production of vocalizations entirely in the high-frequency range by some hummingbirds suggests that at least some species have evolved to hear high-frequency sounds. Recently, it was shown that the Ecuadorian hillstar can hear its high-frequency courtship song above $10 \mathrm{kHz}$ [Duque et al., 2020b]. The hummingbirds showed behavioral changes in attention at the onset of playback of the high-frequency song in the field. They also approached the area surrounding the speaker in response to playback. Additional analysis of neural activity, measured by protein expression of the immediate-early gene $z e n k$, showed robust activity in the secondary auditory areas of the hummingbird brain compared to controls [Duque et al., 2020b]. These results show that the hillstar can hear its courtship high-frequency song and suggests that other hummingbirds producing high-frequency vocalizations hear these sounds too. Nonetheless, detailed characterizations of the auditory curve in the Ecuadorian hillstar and in other hummingbirds are still needed (Fig. 3a).

But how did some species of hummingbirds evolve high-frequency hearing? High-frequency hearing likely involved adaptations at multiple levels, including morphological adaptations in the middle and inner ear as well as neural tuning to the new range of frequencies in the brain's auditory areas. Altogether, these adaptations may have resulted in hummingbirds expanding their hearing range, thus maintaining sensitivity to low-frequency sounds while adding new frequencies to their hearing range (Fig. 3b). This may be the case in species exhibiting a vocal repertoire that spans a wide range of frequencies, like that of the Ecuadorian hillstar. This species produces an aggressive chasing call at frequencies between 2 and 10 $\mathrm{kHz}$ and a courtship high-frequency song that reaches 16 


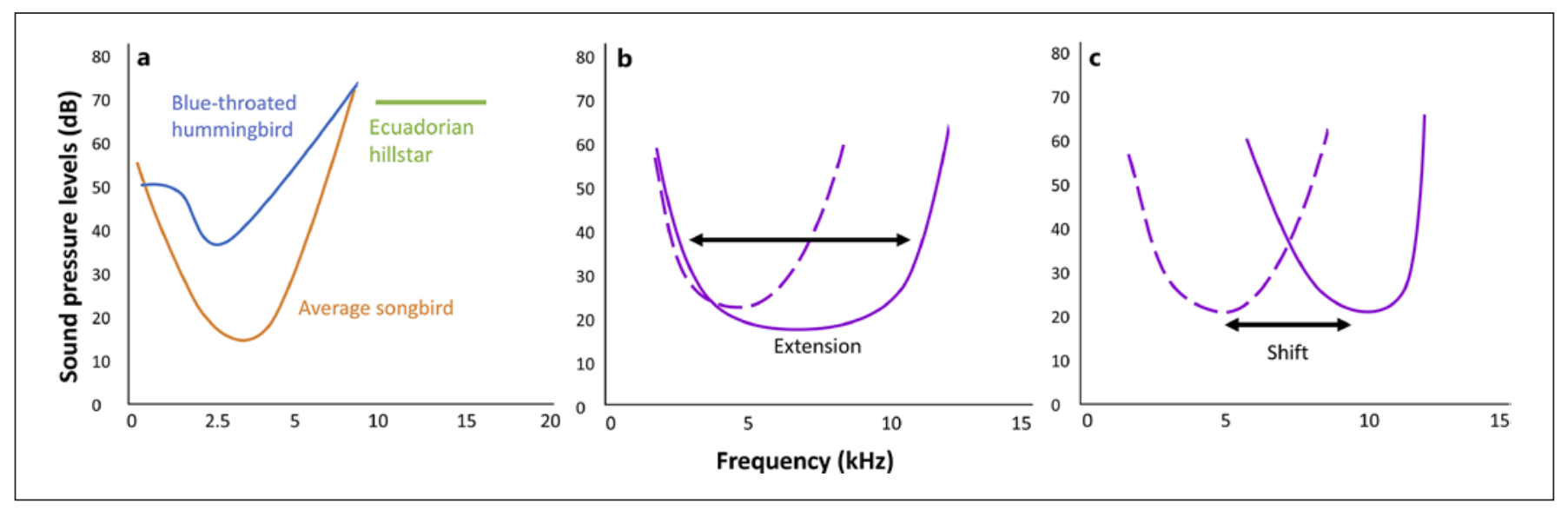

Fig. 3. Hummingbird hearing. a Schematic showing the average hearing curve for a songbird (orange) [Dooling, 2004] and the blue-throated hummingbird (blue) [Pytte et al., 2004]. In green, the frequency range of the high-frequency song that Ecuadorian hillstar individuals can detect [Duque et al., 2020b]; no auditory curve has been characterized for this species yet. b, c Schematic of auditory curves depicting two possible scenarios of how some

$\mathrm{kHz}$. In another scenario, some species may have shifted their auditory sensitivity toward the high-frequency range, losing some sensitivity to low-frequency sounds (Fig. 3c). This less likely scenario could be possible in species whose entire vocal repertoire is restricted to higher frequencies and do not face strong environmental pressures to maintain sensitivity to low-frequency sounds. The Costa's hummingbird is a potential candidate for this "shift" because all its vocalizations are produced at fundamental frequencies above $5 \mathrm{kHz}$ compared to its sister species, the Anna's hummingbird, which vocalizes at lower frequencies [Clark and Feo, 2010]. These differences in vocal production may have arisen in the two sister species as a way to partition the acoustic space and further differentiate from each other. It is possible that the Costa's hummingbird still exhibits auditory sensitivity to lowfrequency sounds despite vocalizing at higher frequencies in order to attend to other biologically relevant sounds in its habitat, such as predator sounds or heterospecific alarm calls in response to the presence of a predator [Haff and Magrath, 2013; Magrath et al., 2015a, b]. While the best hearing sensitivity in a species often matches the dominant frequencies in their songs [Dooling, 1980, 2004], some animals may adapt to hear sounds outside of their vocal range. Some owls can hear high-frequency sounds in spite of not producing any vocalization in that frequency range; instead, they use their remarkable hearing sensitivity to locate their potential prey, rodents hummingbirds may have tuned their auditory sensitivity to highfrequency sounds. High-frequency hearing could be attained by expanding their hearing range (b), or by shifting their sensitivity toward high-frequency sounds (c). Dotted line depicts a hypothetical ancestral state of restricted auditory sensitivity, while solid lines show how hearing may have changed to facilitate the detection of high-frequency sounds.
[Konishi, 1973; Dyson et al., 1998]. These examples highlight the need of conducting more detailed studies characterizing the hearing profile of hummingbird species that exhibit vocal repertoires over a diverse range of frequencies.

Studying the auditory capabilities of hummingbirds will increase our understanding of the diversity of sensory adaptations that facilitate communication. Building auditory curves for hummingbirds using behavioral responses may be one of the best methods to address this gap in the knowledge. In addition to providing behavioral evidence of their hearing sensitivity, behavioral assessments may help researchers to avoid some pitfalls that could arise during ABR procedures. If ABRs or other neurophysiological procedures are conducted, it is important to consider the type of anesthesia and species-specific sensitivity to different anesthetics to guarantee that auditory curves will not be affected by these factors [Thiele and Köppl, 2018]. In addition, considering the life history and physiology of these small birds is crucial. Hummingbirds undergo torpor, a process in which metabolic function and body temperature are lowered, allowing these animals to withstand cold temperatures and survive energy resource depletion during the night [Hiebert et al., 2000; Wolf et al., 2020]. It is unknown whether auditory sensitivity in hummingbirds is altered during torpor, or whether they enter this state during the ABR procedure. Thus, an approach that focuses on behavioral measures 
or a mix of behavioral and neurophysiological assessments should be considered in the study of auditory sensitivity in these birds.

\section{Ecological Factors That Influence Vocal Communication}

Environmental factors impact sound transmission exerting selection pressures on song features. In general, animals living in closed, forested habitats tend to vocalize at lower frequencies than those living in open grassy environments, optimizing their vocalizations for transmission [Morton, 1975; Wiley and Richards, 1978]. In addition to vegetation structure, other environmental features, such as temperature, humidity, and wind, can also affect transmission of a signal [Catchpole and Slater, 2008; Snell-Rood, 2012], all of them exerting pressure on the vocalizations that an animal produces in a particular habitat. Hummingbirds are unique to the Americas, but they are distributed across diverse habitats in the continent, ranging from the rainforest to the high-altitude grasslands [Winkler et al., 2015]. Currently, we know very little about the transmission properties of hummingbird vocalizations in these environments, and how these features relate to the social function of these sounds.

Since high-frequency sounds do not transmit far in closed, forested environments, the presence of high-frequency vocalizations in habitats such as the Andean Cloud Forest [Duque et al., 2018] or the Atlantic Forest [Olson et al., 2018] was surprising. It suggests that some species are exposed to unique environmental pressures that have selected for high-frequency vocalizations to be mostly used as communication signals in close proximity to the intended receiver [Duque et al., 2021]. Ambient noise, a known disruptor of vocal communication via signal masking, is likely playing a role in the evolution of high-frequency vocalizations in some hummingbird species. In the cloud forest, three species of hummingbirds produce high-frequency vocalizations in a bandwidth with little noise interference [Duque et al., 2018] suggesting that these species adapted to broadcast their signals while avoiding signal masking by noise. In the high-altitude grasslands, the Ecuadorian hillstar vocalizes much higher than the noise range produced by wind [Duque et al., 2018]; however, the noise produced by water streams in the territory of the females reaches higher frequencies (approx. $10 \mathrm{kHz}$ ) [Duque, unpubl. data]. The conditions in the females' territories suggest that the high-frequency courtship song in this species also evolved to avoid noise interference during male courtship displays toward females [Duque et al., 2020b]. It remains unknown whether noise and signal masking have also contributed to the evolution of high-frequency vocalizations in the black jacobin in the Atlantic Forest and in other species living in different habitats [Ornelas et al., 2002; Clark et al., 2013; Olson et al., 2018]. More research is necessary to understand the unique suite of environmental pressures that influence hummingbird vocal repertoires, including the evolution of high-frequency vocalizations, in the diverse ecosystems they inhabit.

\section{Conclusion}

The study of vocal behavior and sensory adaptations in hummingbirds is a promising field of research. These charismatic birds exhibit complex vocal behaviors and learning abilities like those found in songbirds and parrots. Some hummingbird species have also evolved unique vocal features such as the production of high-frequency sounds, highlighting the relevance of these birds to study the evolution of novel communication signals and the auditory adaptations that facilitate their use. Furthermore, some hummingbirds also accompany their colorful displays with acrobatic movements, providing opportunities to study the use of multiple modalities of communication, and how these sensory modalities are integrated in the brain of the receiver amid rapidly occurring social interactions.

\section{Acknowledgement}

We would like to honor the legacy of Dr. Walter Wilczynski, mentor and friend. We dearly miss Walt, who enriched our lives not only with his scientific knowledge but with his wisdom, kindness, and warmth. We are lucky to have had him as a mentor and colleague at Georgia State University. His legacy and impact in the neuroethology community will live on to inspire many more generations of scientists. We also want to thank Dr. Christopher Clark for discussions on the Costa's hummingbird and hearing in hummingbirds, Dr. Carlos A. Rodriguez-Saltos for comments on an earlier version of this manuscript, and two anonymous reviewers for their helpful feedback.

\section{Conflict of Interest Statement}

The authors have no conflicts of interest to report. 


\section{Funding Sources}

Funding was provided by the Neuroscience Institute and Center for Behavioral Neuroscience at Georgia State University.

\section{Author Contributions}

Conceptualization, F.G.D., and L.L.C.; writing - original draft, F.G.D.; writing - reviewing and editing, F.G.D., and L.L.C.; funding acquisition, F.G.D. and L.L.C.

\section{References}

Araya-Salas M, Smith-Vidaurre G, Mennill DJ, González-Gómez PL, Cahill J, Wright TF. Social group signatures in hummingbird displays provide evidence of co-occurrence of vocal and visual learning. Proc Biol Sci. 2019; 286(1903):20190666.

Araya-Salas M, Wright T. Open-ended song learning in a hummingbird. Biol Lett. 2013; 9(5):20130625.

Baldassarre DT, Greig EI, Webster MS. The couple that sings together stays together: duetting, aggression and extra-pair paternity in a promiscuous bird species. Biol Lett. 2016; 12(2):20151025.

Baptista LF, Schuchmann K-L. Song learning in the anna hummingbird (Calypte anna). Ethology. 1990;84(1):15-26.

Bostwick KS, Prum RO. High-speed video analysis of wing-snapping in two manakin clades (Pipridae: Aves). J Exp Biol. 2003;206(20): 3693-706.

Bradbury JW, Balsby TJS. The functions of vocal learning in parrots. Behav Ecol Sociobiol. 2016;70(3):293-312.

Bradbury JW, Vehrencamp SL. Principles of animal communication. 2nd ed. Sunderland: Sinauer Associates; 2011.

Burridge J. Spatial evolution of human dialects. Phys Rev X. 2017;7(3):031008.

Campbell P, Pasch B, Pino JL, Crino OL, Phillips M, Phelps SM. Geographic variation in the songs of neotropical singing mice: testing the relative importance of drift and local adaptation. Evolution. 2010;64(7):1955-72.

Capranica RR, Frishkopf LS, Nevo E. Encoding of geographic dialects in the auditory system of the cricket frog. Science. 1973;182(4118): 1272-1275.

Catchpole CK, Slater PJB. Song bird: biological themes and variations. Cambridge: Cambridge University Press; 2008.

Chen A, Field DJ. Phylogenetic definitions for Caprimulgimorphae (Aves) and major constituent clades under the international code of phylogenetic nomenclature. Vertebr Zool. 2020;70(4):571-585.

Clark CJ. Wing, tail, and vocal contributions to the complex acoustic signals of courting Calliope hummingbirds. Curr Zool. 2011;57(2): 187-196.

Clark CJ, Feo TJ. Why do Calypte hummingbirds "sing" with both their tail and their syrinx? An apparent example of sexual sensory bias. Am Nat. 2010;175(1):27-37.
Clark CJ, Feo TJ, Dongen WFDV. Sounds and courtship displays of the Peruvian sheartail, Chilean woodstar, oasis hummingbird, and a hybrid male Peruvian sheartail $\times$ Chilean woodstar. Condor. 2013;115(3):558-575.

Clark CJ, McGuire JA, Bonaccorso E, Berv JS, Prum RO. Complex coevolution of wing, tail, and vocal sounds of courting male bee hum mingbirds. Evolution. 2018a;72(3):630-46.

Clark CJ, Rankin D, Johnson K. Female song in Costa's Hummingbird (Calypte costae). Wilson J Ornithol. 2018b Dec 1;130(4):987-92.

Dooling RJ. Auditory perception in birds. In: Kroodsma DE, Miller EH, editors. Acoustic communication in birds, Vol. 1. Academic Press; 1982. p. 95-130.

Dooling RJ. Audition: can birds hear everything they sing. In: Slabbekoorn H, Marler P, editors. Nature's music: the science of birdsong. San Diego: Elsevier Academic Press; 2004. p. 206-225.

Dooling RJ. Behavior and psychophysics of hearing in birds. In: Popper AN, Fay RR, editors. Comparative studies of hearing in vertebrates. New York: Springer New York; 1980. p. 261-288.

Duque F, Carruth L. Do smaller hummingbirds sing higher pitched songs? Integrative and comparative biology. Cary: Oxford University Press; 2021. p. E215-E216.

Duque F, Monteros M, Nasir I, Uma S, Rodriguez-Saltos C, Carruth L, et al. Dialects in the high-frequency song of a hummingbird. Integrative and comparative biology. Cary: Oxford University Press; 2020a. p. E61.

Duque FG, Rodriguez-Saltos CA, Monteros MF, Wilczynski W. Transmission of high-frequency vocalizations from hummingbirds living in diverse habitats. Biol J Linn Soc. 2021;132(1):148-60

Duque FG, Rodriguez-Saltos CA, Uma S, Nasir I, Monteros MF, Wilczynski W, et al. High-frequency hearing in a hummingbird. Sci Adv. 2020b;6(29):eabb9393.

Duque FG, Rodríguez-Saltos CA, Wilczynski W. High-frequency vocalizations in Andean hummingbirds. Curr Biol. 2018;28(17):R9278.

Düring DN, Ziegler A, Thompson CK, Ziegler A, Faber C, Müller J, et al. The songbird syrinx morphome: a three-dimensional, high-resolution, interactive morphological map of the zebra finch vocal organ. BMC Biol. 2013; 11(1).
Dyson ML, Klump GM, Gauger B. Absolute hearing thresholds and critical masking ratios in the European barn owl: a comparison with other owls. J Comp Physiol A. 1998;182(5): 695-702.

Farabaugh SM, Linzenbold A, Dooling RJ. Vocal plasticity in budgerigars (Melopsittacus undulatus): evidence for social factors in the learning of contact calls. J Comp Psychol. 1994; 108(1):81-92.

Fedy BC, Stutchbury BJM. Territory defence in tropical birds: are females as aggressive as males? Behav Ecol Sociobiol. 2005;58(4):414422.

Feo TJ, Clark CJ. The displays and sonations of the black-chinned hummingbird (Trochilidae: Archilochus alexandri). Auk. 2010; 127(4):787-796.

Ferreira AR, Smulders TV, Sameshima K, Mello CV, Jarvis ED, Yasukawa K. Vocalizations and associated behaviors of the sombre hummingbird (Aphantochroa cirrhochloris) and the rufous-breasted hermit (Glaucis hirsutus). Auk. 2006;123(4):1129-1148.

Ficken MS, Rusch KM, Taylor SJ, Powers DR. Blue-throated hummingbird song: a pinnacle of nonoscine vocalizations. The Auk. 2000 117(1):120-128.

Ficken MS, Rusch KM, Taylor SJ, Powers DR. Reproductive behavior and communication in blue-throated hummingbirds. Wilson Bull. 2002;114(2):197-209.

Ford JKB. Vocal traditions among resident killer whales (Orcinus orca) in coastal waters of British Columbia. Can J Zool. 2011;69(6): 1454-1483

Gahr M. Neural song control system of hummingbirds: comparison to swifts, vocal learning (songbirds) and nonlearning (suboscines) passerines, and vocal learning (budgerigars) and nonlearning (dove, owl, gull, quail, chicken) nonpasserines. J Comp Neurol. 2000 426(2):182-196.

Gaunt SLL, Baptista LF, Sánchez JE, Hernandez D. Song learning as evidenced from song sharing in two hummingbird species (Colibri coruscans and C. thalassinus). Auk. 1994; 111(1):87-103

Gingras B, Boeckle M, Herbst CT, Fitch WT. Call acoustics reflect body size across four clades of anurans. J Zool. 2013;289(2):143-50.

Goller F, Riede T. Integrative physiology of fundamental frequency control in birds. J Physiol Paris. 2013;107(3):230-242. 
González C, Ornelas JF. Song structure and microgeographic song variation in wedge-tailed sabrewings (Campylopterus Curvipennis) in Veracruz, Mexico. Auk. 2005;122(2):593607.

González C, Ornelas JF. Acoustic divergence with gene flow in a lekking hummingbird with complex songs. PLoS One. 2014;9(10): e109241.

González C, Ornelas JF, Gutiérrez-Rodríguez C. Selection and geographic isolation influence hummingbird speciation: genetic, acoustic and morphological divergence in the wedgetailed sabrewing (Campylopterus curvipennis). BMC Evol Biol. 2011;11(38).

Gros-Louis JJ, Perry SE, Fichtel C, Wikberg E, Gilkenson H, Wofsy S, et al. Vocal repertoire of Cebus capucinus: acoustic structure, context, and usage. Int J Primatol. 2008;29:641670

Haff TM, Magrath RD. Eavesdropping on the neighbours: fledglings learn to respond to heterospecific alarm calls. Anim Behav. 2013; 85(2):411-418.

Hiebert SM, Salvante KG, Ramenofsky M, Wingfield JC. Corticosterone and nocturnal torpor in the rufous hummingbird (Selasphorus rufus). Gen Comp Endocrinol. 2000;120(2): 220-234.

Hogan BG, Stoddard MC. Synchronization of speed, sound and iridescent color in a hummingbird aerial courtship dive. Nature Commun. 2018;9:5260.

Hunter TA. On the role of wing sounds in hummingbird communication. Auk. 2008;125(3): 532-541.

Janik VM. Whistle matching in wild bottlenose dolphins. Science. 2000;289(5483): 13551357.

Janik VM, Knörnschild M. Vocal production learning in mammals revisited. Phil Trans $\mathrm{R}$ Soc B. 2021;376:20200244.

Janik VM, Slater PJB. Vocal learning in mammals. In: Slater PJB, Rosenblatt JS, Snowdon CT, Milinski M, editors. Advances in the study of behavior. Academic Press; 1997. p. 59-99.

Jarvis ED. Learned birdsong and the neurobiology of human language. Ann N Y Acad Sci. 2004;1016(1):749-77.

Jarvis ED, Ribeiro S, da Silva ML, Ventura D, Vielliard J, Mello CV. Behaviourally driven gene expression reveals song nuclei in hummingbird brain. Nature. 2000;406:628-632.

Johnson F, Soderstrom K, Whitney O. Quantifying song bout production during zebra finch sensory-motor learning suggests a sensitive period for vocal practice. Behav Brain Res. 2002;131(1):57-65.

Johnson KE, Clark CJ. Ontogeny of vocal learning in a hummingbird. Anim Behav. 2020;167: 139-150.

Jones B, Zapetis M, Samuelson MM, Ridgway S. Sounds produced by bottlenose dolphins (Tursiops): a review of the defining characteristics and acoustic criteria of the dolphin vocal repertoire. Bioacoustics. 2020;29(4):399-440.
Konishi M. How the owl tracks its prey. Am Sci. 1973;61(4):414-424

Kroodsma D. The diversity and plasticity of birdsong. In: Slabbekoorn H, Marler P, editors. Nature's music: the science of birdsong. San Diego: Elsevier Academic Press; 2004. p. 108131.

Lara C, Martínez-García V, Ornelas JF. Microgeographical variation in song repertoire and structure between the leks of green violetears Colibri thalassinus in Central Mexico. Acta Ornithol. 2015;50(1):23-32.

Lohr B, Dooling RJ. Hearing in the Ruby-throated hummingbird (Archilochus colubris: Trochilidae). Daytona Beach: Association for Research in Otolaryngology; 2004. p. 56.

Magrath RD, Haff TM, Fallow PM, Radford AN. Eavesdropping on heterospecific alarm calls: from mechanisms to consequences. Biol Rev Camb Philos Soc. 2015a;90(2):560-86.

Magrath RD, Haff TM, McLachlan JR, Igic B. Wild birds learn to eavesdrop on heterospecific alarm calls. Curr Biol. 2015b Aug 3; 25(15):2047-50.

Mann NI, Dingess KA, Slater PJ. Antiphonal four-part synchronized chorusing in a neotropical wren. Biol Lett. 2006;2:1-4.

Marler P, Böhner J, Chaiken M. Repertoire turnover and the timing of song acquisition in European starlings. Behaviour. 1994;128(1-2): 25-39.

Marler P, Tamura M. Song "dialects" in three populations of white-crowned sparrows. Condor. 1962;64(5):368-377.

McGuire JA, Witt CC, Altshuler DL, Remsen JV, Zamudio K, Sullivan J. Phylogenetic systematics and biogeography of hummingbirds: Bayesian and maximum likelihood analyses of partitioned data and selection of an appropriate partitioning strategy. Syst Biol. 2007; 56(5):837-856.

McGuire JA, Witt CC, Remsen JV, Corl A, Rabosky DL, Altshuler DL, Dudley R. Molecular phylogenetics and the diversification of hummingbirds. Curr Biol. 2014;24(8):910916.

Monte A, Cerwenka AF, Ruthensteiner B, Gahr $\mathrm{M}$, Düring DN. The hummingbird syrinx morphome: a detailed three-dimensional description of the black jacobin's vocal organ. BMC Zool. 2020;5:7.

Morton ES. Ecological sources of selection on avian sounds. Am Nat. 1975;109(965):17-34.

Mountjoy DJ, Lemon R. Song as an attractant for male and female European starlings, and the influence of song complexity on their response. Behav Ecol Sociobiol. 1991;28:97100.

Nelson DA. A preference for own-subspecies' song guides vocal learning in a song bird. Proc Natl Acad Sci USA. 2000;97(24):1334813353.

Nottebohm F. The origins of vocal learning. Am Nat. 1972;106(947):116-140.

Nowicki S, Searcy WA. The evolution of vocal learning. Curr Opin Neurobiol. 2014;28:4853.
Olson CR, Fernández-Vargas M, Portfors CV, Mello CV. Black Jacobin hummingbirds vocalize above the known hearing range of birds. Curr Biol. 2018;28(5):R204-R205.

Ornelas JF, González C, Uribe J. Complex vocalizations and aerial displays of the amethystthroated Hummingbird (Lampornis amethystinus). Auk. 2002;119(4):1141-1149.

Ortiz-Crespo FI. Los colibries: historia natural de unas aves casi sobrenaturales. Autor; 2003.

Pettitt BA, Bourne GR, Bee MA. Quantitative acoustic analysis of the vocal repertoire of the golden rocket frog (Anomaloglossus beebei). J Acoust Soc Am. 2012;131(6):4811-4820.

Planqué R, Britton NF, Slabbekoorn H. On the maintenance of bird song dialects. J Math Biol. 2014;68:505-531.

Pytte C, Ficken MS. Aerial display sounds of the black-chinned hummingbird. Condor. 1994; 96(4):1088-1091.

Pytte C, Ficken M, Moiseff A. Ultrasonic singing by the blue-throated hummingbird: a comparison between production and perception. J Comp Physiol A. 2004;190:665-673.

Reiner A, Perkel DJ, Bruce LL, Butler AB, Csillag A, Kuenzel W, et al. The avian brain nomenclature forum: terminology for a new century in comparative neuroanatomy. J Comp Neurol. 2004;473:E1-E6.

Riebel K. The "mute" sex revisited: vocal production and perception learning in female songbirds. Adv Study Behav. 2003;33:49-86.

Riede T, Olson CR. The vocal organ of hummingbirds shows convergence with songbirds. Sci Rep. 2020;10:2007.

Ryan MJ, Brenowitz EA. The role of body size, phylogeny, and ambient noise in the evolution of bird song. Am Nat. 1985;126(1):87100

Ryan MJ, Tuttle MD, Rand AS. Bat predation and sexual advertisement in a neotropical anuran. Am Nat. 1982;119:136-139.

Salinas-Melgoza A, Wright TF. Evidence for vocal learning and limited dispersal as dual mechanisms for dialect maintenance in a parrot. PLoS One. 2012;7(11):e48667.

Schuchmann K-L. Family Trochilidae (hummingbirds). In: Del Hoyo J, Elliott A, Sargatal J, editors. Handbook of the birds of the world, Vol. 5. Barcelona: Lynx Edicions; 1999. p. 468-535.

Slater PJB, Mann NI. Why do the females of many bird species sing in the tropics? J Avian Biol. 2004;35(4):289-94

Snell-Rood EC. The effect of climate on acoustic signals: does atmospheric sound absorption matter for bird song and bat echolocation? J Acoust Soc Am. 2012;131:1650.

Snow D. The singing assemblies of little hermits. Living Bird. 1968;7:47-55.

ten Cate C. Re-evaluating vocal production learning in non-oscine birds. Phil Trans R Soc B. 2021;376:20200249.

ten Cate C, Fullagar PJ. Vocal imitations and production learning by Australian musk ducks (Biziura lobata). Phil Trans R Soc B. 2021;376: 20200243. 
Thiele N, Köppl C. Gas anesthesia impairs peripheral auditory sensitivity in barn owls (Tyto alba). eNeuro. 2018;5(5).

Vicario DS, Nottebohm F. Organization of the zebra finch song control system: I. Representation of syringeal muscles in the hypoglossal nucleus. J Comp Neurol. 1988;271(3):346-54.

Wells S, Bradley RA, Baptista LF. Hybridization in Calypte hummingbirds. Auk. 1978;95:537549.

Wiley RH. Song groups in a singing assembly of little hermits. Condor. 1971;73(1):28-35.
Wiley RH, Richards DG. Physical constraints on acoustic communication in the atmosphere: implications for the evolution of animal vocalizations. Behav Ecol Sociobiol. 1978;3(1): 69-94.

Wilkins MR, Odom KJ, Benedict L, Safran RJ. Analysis of female song provides insight into the evolution of sex differences in a widely studied songbird. Anim Behav. 2020;168:6982.

Winkler DW, Billerman SM, Lovette IJ. Bird families of the world: an invitation to the spectacular diversity of birds. Lynx Edicions; 2015.
Wolf BO, McKechnie AE, Schmitt CJ, Czenze ZJ, Johnson AB, Witt CC. Extreme and variable torpor among high-elevation Andean hummingbird species. Biol Lett. 2020;16(9):20200428.

Wolf LL. Female territoriality in a tropical hummingbird. Auk. 1969;86(3):490-504.

Wycherley J, Doran S, Beebee TJC. Frog calls echo microsatellite phylogeography in the European pool frog (Rana lessonae). J Zool. 2002; 258(4):479-484.

Zusi RL. Introduction to the skeleton of hummingbirds (Aves: Apodiformes, Trochilidae) in functional and phylogenetic contexts. Ornithol Monogr. 2013;77(1):1-94. 